Research Article

\title{
Dye Sensitized Solar Cells with Low Cost Carbon Nanotubes Electrodes
}

\author{
F. M. Al-Marzouki, S. Abdalla, and S. Al-Ameer \\ Department of Physics, Faculty of Science, King Abdulaziz University Jeddah, P.O. Box 80203, Jeddah 21589, Saudi Arabia
}

Correspondence should be addressed to S. Abdalla; smabdullah@kau.edu.sa

Received 20 October 2015; Revised 24 December 2015; Accepted 3 January 2016

Academic Editor: Gonzalo Martínez-Barrera

Copyright (C) 2016 F. M. Al-Marzouki et al. This is an open access article distributed under the Creative Commons Attribution License, which permits unrestricted use, distribution, and reproduction in any medium, provided the original work is properly cited.

\begin{abstract}
Dye sensitized solar cells (DSSCs) are very sensitive to electrodes, due to either high cost or easy corrosion problems. To minimize these factors, we present DSSCs with cheap carbon nanotubes as counter electrodes. In addition, we suggest replacing the electrolyte (in typical DSSCs) with a solid film of powdered $\mathrm{CsSnI}_{3}$. The electrical behavior ( $I-V$ characteristics) of the proposed device has been measured for different shading conditions. In the light of a theoretical model based on the presence of two diodes, the experimental data have been explained, taking into account a new equivalent circuit for the DSSC. These DSSCs may receive different levels of sun radiation, which stimulates the study of partial shading; so, we have studied the effect of different shadow rates on the solar conversion efficiency of a unit of 4 -W-connected DSSCs. The validity of the present model has been examined by fitting it into $I-V$ characteristics at different shading rates.
\end{abstract}

\section{Introduction}

Due to the enormous acceleration of modern civilization and the developments in all domains all over the world, the increase in the rate of energy consumption is a characteristic of this civilization, and a dire need for energy is always present. However, the exhausted energy sources, such as mineral and animal traces, are inevitably disappearing, and solar energy has become an increasingly hot topic, particularly over the recent years. For example, an enormous quantity of energy is supplied each second, to the earth's surface (about $9.5 \times 10^{16}$ Joule/second [1]). In their pioneer work, O'Regan and Grätzel [2] have initiated the principals of dye sensitized solar cells (DSSCs). Since 1990s, DSSCs have continuously augmented by time as it is illustrated in Figure 1. In this figure, the number of publications of CNTs has been reported and CNTs have been extensively used as counter electrode. Due to the high rate of publications, several huge companies have commercialized these solar cells. As a consequence, the fabrication methods for CNT films and photoelectrode materials have been developed. Table 1 shows the different fabrication methods of DSSCs.
Grätzel has reported that this quantity of energy is ten thousand times more than mankind needs, nowadays.

This means that only a slim part of the global surface area, which is about $0.1 \%$, with a solar efficiency of about $10 \%$, would be totally enough to cover our energy needs. Consequently, the solar energy cells have received increasing attention over the last three decades. They have passed through several substantial steps, starting with simple solar cell [3], to a second main step, solar cells based on thin film solar cells (SCs) $[4,5]$ and the present third generation which uses organic-SC and dye sensitized solar cells [5-8]. In addition, the third generation has more compatibility with flexible substrate and relatively low cost of basic materials.

Furthermore, nanotechnology launches several axes of research, particularly in nanoenergy. For example, it is now easy to prepare a suitable nanomaterial with different nanostructures, using the dye sensitized solar cells to get the optimum converted energy. Moreover, one can paint a glass slide with carbon nanotubes (CNTs) and consider it as an active electrode (working electrode), which is placed against another similar glass slide which represents a counter electrode. This is illustrated in Figure 2, where the space 


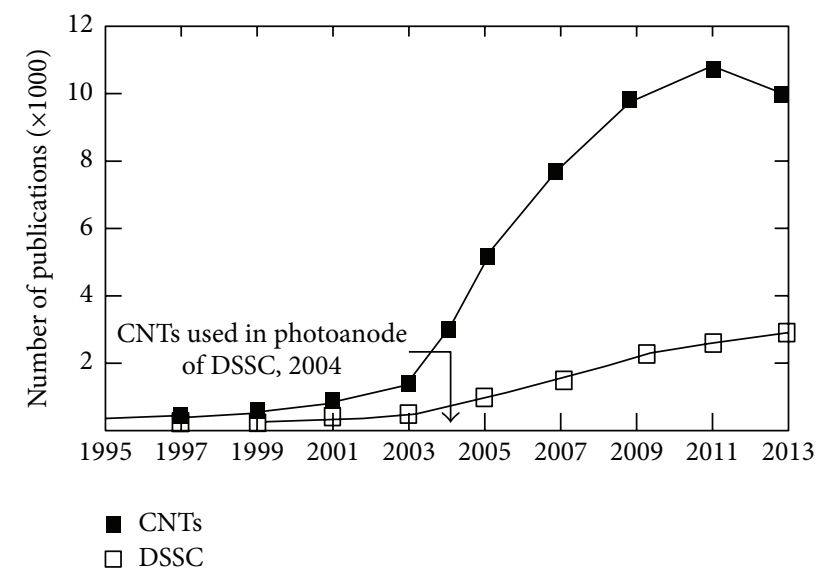

FIgURE 1: Rise of publications number, concerning nanotubes and DSSCs, with time.

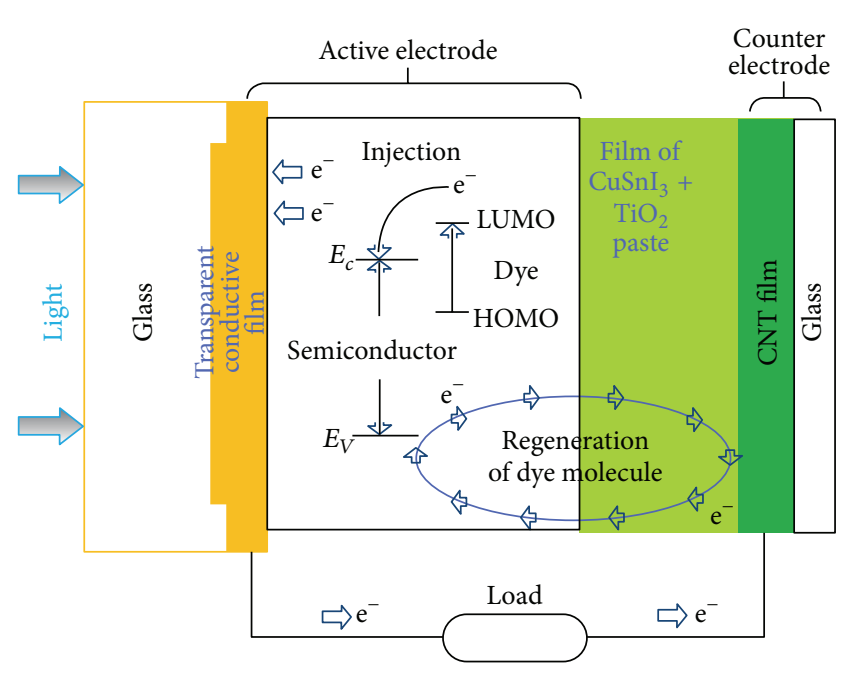

FIGURE 2: Schematic illustration shows the proposed dye sensitized solar cells.

between these electrodes lies in the micron scale $\sim 40 \mu \mathrm{m}$, and it contains solid electrolyte acting as a high conductance medium. This illustration makes the active electrode irradiate photons which are transferred to the transparent electrode, and they arrive at the photoanode, where they will be absorbed by the sensitive-dye molecules.

The electron transition from the Highest Occupied Molecular Orbitals (HOMO) to the Lowest Unoccupied Molecular Orbitals (LUMO) is due to the optical absorption which occurs in the dye molecule [6]. These photogenerated electrons are transferred from the dye molecule towards the oxide and then spread out towards the counter electrode, where the cell is directly connected to the output load resistance. The dye molecules collect photons from the incident light, in a manner similar to the role of an antenna. This opens the doors for more progression of this technique, and for the development of more different organic dyes [9-11]. Photons, with energy $E=h v$, stimulate an electron from the dye to the LUMO of the semiconductor, where it reaches the bottom electrode. The electrolyte reduces the dye molecules, which create tri-iodide ions $\mathrm{I}_{3}{ }^{-}$as follows: $3 \mathrm{I}^{-} \rightarrow \mathrm{I}_{3}{ }^{-}+$ $2 \mathrm{e}^{-}$. The external load will then absorb the energy of the electron via electrons transfer, through the wires of the external circuit. The tri-iodine ions $\left(\mathrm{I}_{3}{ }^{-}\right)$pass through the solution to the corresponding electrode where it will be reduced and thus complete the electrical circuit. Here, the semiconductor is nanoporous $\mathrm{TiO}_{2}$, which has a relatively high surface area. This large area increases the activity of dye molecules, but, at the same time, it reduces the rate of electron migration. Different semiconductors have been investigated, in order to get higher mobility of current carriers [12, 13]. In manufacturing DSSCs, several materials and techniques have been used: engineered semiconductor quantum dots, metal-free organic dyes, C60, and different materials. Using recent techniques with carbon nanotubes (CNTs) [14, 15], an alternative (and cheaper) to these techniques and materials has been offered. These tubes are highly conductive, photoactive, and mechanically strong, if well-prepared using different methods. For example, CNTs prepared by CVD are chemically inactive. CNTs show favorable features as counter electrodes [16].

Despite offering relatively high conversion efficiency, serious problems of life duration are strongly associated with the use of typical dye sensitized solar cells. First, problems associated with the electrodes result from the use of organic liquids ionic solutions with $\mathrm{I}^{-} / \mathrm{I}_{3}{ }^{-}$, which reacts with the electrode leading to strong corrosion, in addition to the problems of solution loss by leakage process. Second, DSSCs should not rely on dyes, because they are weakened by time (bleaching effect of time), which limits the technical use of this technology. Third, platinum, which is often used as a counter electrode, has been inconvenient for use as a noble metal.

This largely inhibits the use of DSSCs on a commercial scale. Fourth, the rare indium is an undesired metal on the commercial scale. So, to minimize or even to overcome these factors that resist the large application of DSSCs, in this research work, we suggest that the extraordinary properties of carbon nanotubes should be used to build a commercial solar cell with relatively high conversion efficiency. In addition, we suggest replacing the electrolyte with a solid film of powdered $\mathrm{CsSnI}_{3}$ "diffused" into $\mathrm{TiO}_{2}$ (below the painted glass), as shown in Section 2. This replacement will eliminate the problem of using electrolyte as iodine ions.

Till now, only few papers have dealt with data concerning solar illumination, with different shadow rates on DSSCs conversion efficiency. In these papers, the forward bias electrical $I-V$ characteristics are shown, taking into account the charge neutrality (via the continuity equation), through the semiconductors of the cell. But, on the contrary, the well known model of Butler-Volmer (BVM) takes into consideration the reverse bias, when polarizing the solar cell. Moreover, BVM was adopted by Chen et al. [17] and De Marco et al. [18]; however, the experimental data of partially or totally shadowed $I-V$ characteristics are not completely fitted with one of these two models or even by some accord between these two models. Taking these points into account, this research work will deal with the elaboration of an 
TABLE 1: Developments of different fabrication methods of DSSCs.

\begin{tabular}{|c|c|c|c|c|}
\hline $\begin{array}{l}\text { Production } \\
\text { method }\end{array}$ & Advantage & Disadvantage & Year & Reference \\
\hline $\begin{array}{l}\text { Aerosol depositing } \\
\text { (Wet Route) }\end{array}$ & $\begin{array}{l}\text { Performance films } \\
\text { and mass production }\end{array}$ & $\begin{array}{c}\text { High cost, high } \\
\text { temperature, } \\
\text { complicated processes }\end{array}$ & 2011 & {$[26]$} \\
\hline $\begin{array}{l}\text { Array-drawing } \\
\text { (Wet Route) }\end{array}$ & High efficient cells & $\begin{array}{l}\text { Small production and } \\
\text { difficult to control }\end{array}$ & 2010 & {$[27]$} \\
\hline $\begin{array}{l}\text { Transfer printing } \\
\text { (Dry Route) }\end{array}$ & $\begin{array}{l}\text { High performance, } \\
\text { low cost, and simple } \\
\text { method }\end{array}$ & $\begin{array}{l}\text { Limitation of film } \\
\text { size, limitation to } \\
\text { control the } \\
\text { manufacturing } \\
\text { method }\end{array}$ & 2006 & {$[28]$} \\
\hline $\begin{array}{l}\text { Dip-coating (Dry } \\
\text { Route) }\end{array}$ & $\begin{array}{l}\text { Cheap and simple } \\
\text { method }\end{array}$ & $\begin{array}{l}\text { Hard to control film } \\
\text { thickness }\end{array}$ & 2012 & {$[29]$} \\
\hline $\begin{array}{l}\text { Spin-coating (Dry } \\
\text { Route) }\end{array}$ & $\begin{array}{l}\text { Mass production, } \\
\text { cheap and simple } \\
\text { method }\end{array}$ & $\begin{array}{l}\text { Loss of CNTs through } \\
\text { fabrication and } \\
\text { creation of } \\
\text { inhomogeneous films }\end{array}$ & 2010 & {$[30]$} \\
\hline $\begin{array}{l}\text { Spray-coating (Dry } \\
\text { Route) }\end{array}$ & $\begin{array}{l}\text { Rapid process, mass } \\
\text { production, cheap } \\
\text { and simple method }\end{array}$ & $\begin{array}{c}\text { Creation of rude } \\
\text { surfaces with possible } \\
\text { aggregation of CNTs }\end{array}$ & 2010 & {$[31]$} \\
\hline EPD (Dry Route) & $\begin{array}{l}\text { Cheap, rapid, and } \\
\text { large area films }\end{array}$ & $\begin{array}{l}\text { Hard to control the } \\
\text { film thickness and } \\
\text { limited substrate }\end{array}$ & 2008 & {$[32]$} \\
\hline $\begin{array}{l}\text { Printing (Dry } \\
\text { Route) }\end{array}$ & $\begin{array}{l}\text { Possibility of using } \\
\text { different substrates, } \\
\text { simple and fast }\end{array}$ & $\begin{array}{l}\text { Hard to control the } \\
\text { film thickness }\end{array}$ & 2009 & {$[33]$} \\
\hline $\begin{array}{l}\text { Brush painting } \\
\text { (Dry Route) }\end{array}$ & $\begin{array}{l}\text { Mass production, } \\
\text { cheap and rapid } \\
\text { deposition }\end{array}$ & $\begin{array}{l}\text { Hard to control the } \\
\text { film thickness }\end{array}$ & 2014 & {$[34]$} \\
\hline
\end{tabular}

adequate model to explain clearly the electrical behavior and $I-V$ characteristics of DSSCs with partly or completely shadowing conditions. So, we will modify the well known one-diode model of a photovoltaic cell, using another diode. Thus, the cell will be represented by two diodes: one accounts for the forward bias and the other accounts for the reverse bias. The presented model is, thus, adopted to investigate the different illumination effects on a DSSC, made of 4 seriesconnected elements.

Finally, Slonczewski and Weiss [19] compared the ratio of energy produced per dollar, to the cost of installation and manufacturing, and they discovered that the use of graphite was an excellent solution in producing low cost cells [19] with relatively high efficiency which we took into account when we replaced them with CNTs, instead of graphite.

The literature is not poor in the application of CNTs as the counter component of the counter electrode of DSSCs [2023]. Mixing aerosol with chemical evaporation deposition, Aitola et al. [21] have produced single-walled carbon nanotubes and have deposited film on polyethylene terephthalate substrate. Their plastic films have surface electrical resistance about $60 \mathrm{ohms} \mathrm{sq}^{-1}$ when using CNT film as transparent conducting film (TCF) for DSSC. Their data have given $0.74 \%$ solar conversion efficiency at an intensity $100 \mathrm{~mW} / \mathrm{cm}^{2}$ which is by far inferior to the reference cell (4.4\%). Experimental data [24] have improved the efficiency of DSSCs using Pt-free and transparent conductive oxide-free counter electrode and $\mathrm{N}$-doped CNTs. The use of this doping on carbon nanotubes creates an extra free electron which can be used in reduction of electrolyte at high rate leading to increase of the efficiency. This efficiency has been improved to reach 1.5\% [21]. Carbon nanotubes have been, also, used as an alternative to transparent conducting oxide materials in the Pt-based counter electrode of DSSC [25].

\section{Materials and Methods}

2.1. Cell Assembling (Figure 3). First, a comparison between the structure of a typical DSSC and a solid dye sensitized solar cell with carbon nanotubes is suggested. The enriched carbon nanotube solar cell (CNTSC) consists of the following:

(1) A mixture of $90 \%$ semiconducting nanotubes and $10 \%$ metallic nanotubes, "South/West Nano Technologies," with a length of about $2.4 \mu \mathrm{m}$ and diameter of about $1.5 \mathrm{~nm}$ was used.

(2) A thick film of powdered $\mathrm{CsSnI}_{3}$ "diffused" into $\mathrm{TiO}_{2}$ (below the painted glass). This thick film was prepared, using the method described by Chung et al. [35]. The advantage of using $\mathrm{CsSnI}_{3}$ was the diffusion of SC into nanoporous $\mathrm{TiO}_{2}$ and it could be stabilized at a solid phase inside $\mathrm{TiO}_{2}$ [35]. In their 


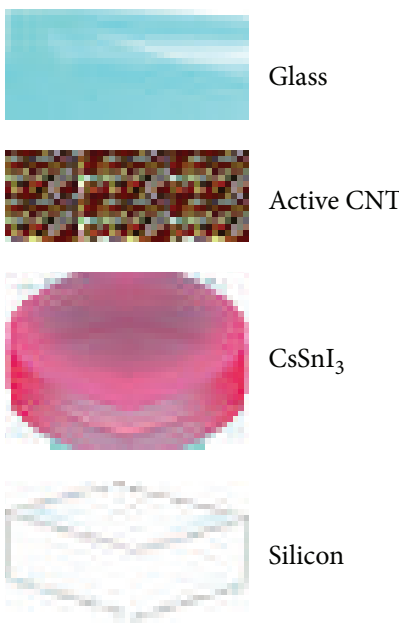

(a)

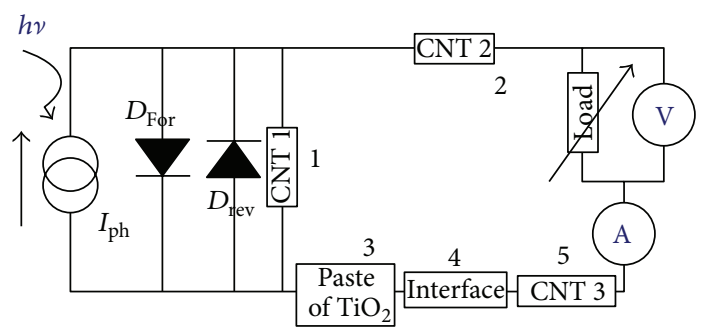

(c)

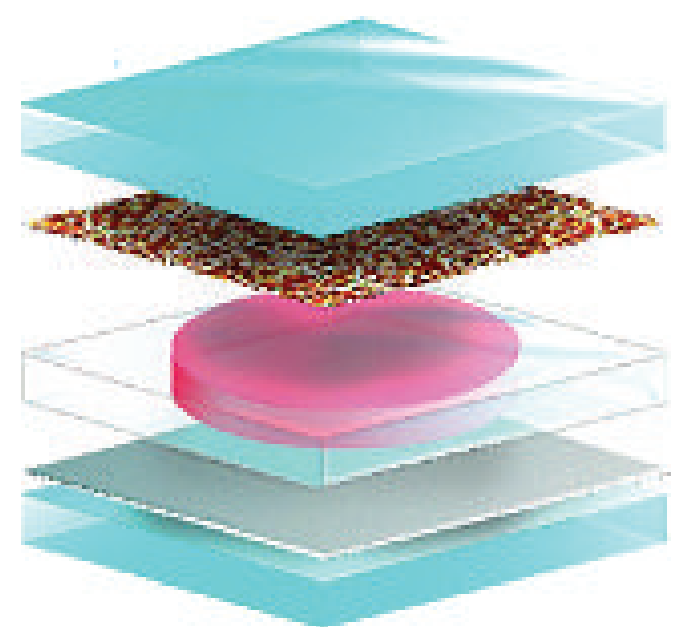

(b)

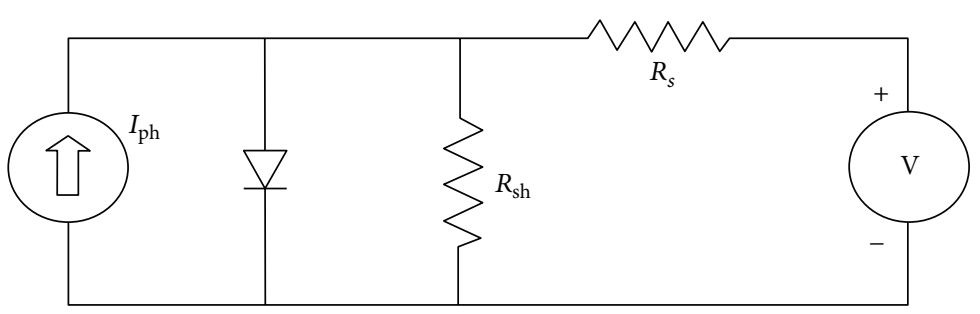

(d)

FIGURE 3: Schematic design of carbon nanotube solar cells (CNTSCs) and their equivalent electronic-circuits using the model of [36]. Figures 3(a) and 3(b) represent a CNTSCs construction where a glass slide (bluish-green) is followed by an active $\mathrm{CNT}_{\text {film }}$ then film of CsSnI ${ }_{3}$ with porous $\mathrm{TiO}_{2}$ paste (red) followed by silicon insulator and CNT counter electrode (black) deposited on glass slide (bluish-green). Figure 3(c) shows the equivalent circuit of CNTSCs where the numbers stand for 1- Carbon nanotube film-1, 2- Carbon nanotube film-2, 3- Paste 4interface 5- Carbon nanotube film-3 and 6- electric resistance load. The last part represents a typical "one-diode" equivalent circuit for a dye sensitized solar cell (DSSC). Figure 3(d) represents the equivalent circuit of typical one-diode circuit.

method, there were no by-products and consequently the compound was not only stable against high temperatures, but also strong against chemical reactions, in contrast to the most known solar cells [35]. This study showed that carbon nanotubes (CNTs) could replace the counter electrode. This presented it as a useful utility because the CNTs were chemically inert and corrosion of electrodes was very difficult with these tubes.

(3) A film of semiconducting nanotubes (instead of the indium oxide in DSSCs) was used.

(4) A film of CsSnI $I_{3}$ with a porous $\mathrm{TiO}_{2}$ paste (instead of the electrolyte in DSSCs) was used.

(5) For photoconversion, semiconducting carbon nanotubes were used (instead of the dye in DSSCs).

(6) A film of Mixed Carbon Nanotubes (MCNTs) was used as a counter electrode (instead of the platinum electrode in DSSCs), "South/West Nano Technologies," with a length of about $2.4 \mu \mathrm{m}$ and diameter of about $1.5 \mathrm{~nm}$.
(7) MCNTs were composed of mixtures of $66 \%$ semiconducting nanotubes and 33\% metallic nanotubes (Carbon Nanotechnologies, “UNIDYM ${ }^{\bullet}$ Inc.”).

Dispersion of CNTs was carried out, using ultrasound agitation in 1,2-dichloroethane for about one hour for the regular mixture and for about four hours for the enriched mixture. Using spray paint technique, the dispersion was dyed (using a technique of airbrush) onto a glass substrate. In a regular manner, the painted glass slides were rotated while spraying, in order to obtain a homogeneous painting. The glass slides were heated on a hot plate, in order to get rid of what they might present to the solvents. The exposed surface area of about $4.8 \mathrm{~mm}^{2}$ resulted from the obtained solar cell, with an interelectrode distance of about $2.5 \mathrm{~mm}$. The glass slides were about one mm thick.

2.2. Production of Solar Energy. The cell was connected to a resistor $\left(R_{L}\right)$. The latter varied in the range of $0<R_{L}<10 \mathrm{M} \Omega$ and was connected to a current amplifier. The current $I$ (and the voltage $V$ across $R_{L}$ ) was measured, as a function of the load resistor $R_{L}$. The cell was subjected to solar radiation with 
an average flux of about $890 \mathrm{~W} / \mathrm{m}^{2}$. We used a vast range of CNTs concentrations to build up DSSCs.

\section{Model}

3.1. Theoretical Aspects. The driving forces acting on the photogenerated electrons transportation in $\mathrm{TiO}_{2}$ occur due to the diffusion mechanism, rather than due to the action of the electric field [37] (the same applies to the holes in the paste). In fact, the miniscule volume of $\mathrm{TiO}_{2}$ nanoparticles (from $20 \mathrm{~nm}$ to $70 \mathrm{~nm}$ ) creates an important space charge layer. Also, O'Regan et al. [38] and Grätzel [39] have shown that the sintered particles are usually surrounded by an excess of charges from the paste that screens any electric field in the region. Sodergern et al. [40] used the recombination, generation, and electron transport rates, to estimate the electron collection efficiency of the nanostructured photoactive electrode. While developing our model, their model [40] was taken into account.

Here, one can describe the neutrality of charges as

$$
\frac{\partial n}{\partial t}=D \frac{\partial^{2} n}{\partial x^{2}}-\frac{n-n_{0}}{\tau}+g
$$

where $n$ is the free electron density, " $\tau$ " is the electron lifetime, $D$ is the diffusion coefficient, $g$ is the generation rate of electrons, and $n_{0}$ is the electron density in an equilibrium state in a dark condition. Consider the following boundary conditions:

$$
\begin{aligned}
\left.n\right|_{x=0} & =n_{0} \exp \left(\frac{q V}{m k T}\right), \\
\frac{\partial n}{\partial x}_{x=d} & =0,
\end{aligned}
$$

where $V$ represents the photoelectrode potential, which is related to the energy variation between the electrode potential and Fermi energy (Fermi level), $E_{F}$. Consequently, the current density equation is given as

$$
j=j_{\mathrm{SC}}-j_{0} \exp \left(\frac{q V}{m k T}-1\right) \text {. }
$$

It is important to note that an ideality factor $m$ is considered, when applying (2). Bashahu and Nkundabakura [41] identified a value of $m$ to be about 22, from experimental data that considered only one set of current-voltage experimental data. Due to the inevitable presence of a parasitic resistance $R_{s}$, only the last equation cannot describe the electric $I-V$ characteristics data. This resistance should be introduced as series resistance $R_{s}$ to get an exact estimation of the currentvoltage characteristics. In addition, this parasitic resistance $R_{s}$ contains the resistive effects of the metallic contacts. Another parasitic resistance $R_{\text {sh }}$ should also be considered, due to the presence of a parallel electric field, which is present due to the leakage path across the interface between $\mathrm{TiO}_{2}$ and the paste. In order to understand the $I-V$ characteristics and to simulate an equivalent circuit that described the electrical characteristics of DSSC, Halm et al. [42] developed the classic "one-diode" model (Figure 1) that sufficiently described the following $I-V$ characteristics:

$$
I=I_{\mathrm{ph}}-I_{0}\left[\exp \left(\frac{q\left(V+I R_{s}\right)}{m k T}\right)-1\right]-\frac{V+I R_{s}}{R_{\mathrm{sh}}},
$$

where $I_{0}$ is the current density at saturation-reversed conditions, $I_{\mathrm{ph}}$ is the photocurrent density of the diode as a current source, $q$ is the electron charge, $k$ is Boltzmann constant, $T$ is the absolute temperature, and $R_{\text {sh }}$ is a parallel electric resistance connected to the cell. Considering this with $I=0$, the open circuit voltage $V_{\mathrm{OC}}$ can be given as

$$
V_{\mathrm{OC}}=\frac{m k T}{q} \ln \left(\frac{I_{\mathrm{ph}}}{I_{0}}+1\right) \text {. }
$$

This last equation gives the reason why $V_{\text {OC }}$ corresponds with the high growing current of the short circuit. But the finely built current of the dye cells is not too simple to be described by only one diode, because it will be poorly described and it cannot be used to explain the electrical behavior of DSSC. Another important factor is that the parasitic resistances $R_{s}$ and $R_{\text {sh }}$ are considered to be independent of the voltage, which is not the real case. However, these fitting parameters represent an effective tool that is used to have a first sight interpretation of the characteristic behavior of the $I-V$ [43].

3.2. Reverse Behavior through Dye Sensitized Solar Cells. Sastrawan et al. [44] and Chen et al. [17] have shown that the generated photocurrent produced when cells are collected together makes the shaded cell operate in reverse bias. The counter electrode (platinum or else) supplies electrons to the paste, which facilitates possible and easier ways of injecting electrons from the paste, and thus the charges will transfer from the corresponding electrode $\left(\mathrm{I}^{-}\right)$directly to the porous $\mathrm{TiO}_{2}$, and the oxidation of the electrode $\left(\mathrm{I}^{-}\right)$allows one to consider the reverse current passage making a possible introduction to a reverse diode, in addition to the forward one (Figure 3).

Wolf and Rauschenbach [45] have shown that the charge transfer is mainly due to a reduction in the oxidation reaction (in the shadowed cell), and the recombination via the substrate. Following this, the net flow of charges yielded a current given by BVM and it was written in terms of overvoltage as

$$
j=j_{0}\left[\exp \left(\frac{\beta(q n) V}{k T}\right)-\exp \left(\frac{-(1-\beta)(q n) V}{k T}\right)\right],
$$

where $\beta$ is the cathodic transfer coefficient, $j_{0}$ is the exchange current density, and $n$ is the number of transferred electrons. Both $\left(\mathrm{I}^{-}\right)$and $\left(\mathrm{I}^{-}\right)_{3}$ affected the current density (which was going to the cathode) via the concentrations and the reaction area. Here, the first term, in (7), is a linear function of the current, but the other term is a linear function of the current going to the anode. Moreover, the direct relationship between the two currents going to the anode and cathode resulted in the exchange current $j_{0}$. In fact, BVM gave the reasons about the homogeneity of the electric field around the electrodes 
[46]. Some limitations, however, arose, because of a small correction of the overpotential at the counter electrode, which was essential for fitting current-voltage characteristics in an effective way [47]. Chen et al. [17] introduced the idea of $R_{s}$ of the transparent conductive oxide layers of the BVM, which improved the fitting process of the cell's electrical characteristics.

3.3. Electrical Behavior of DSSC. In the equivalent circuit, the rectification behavior of the diode explained the electrical behavior of DSS at the reverse polarization conditions. We proposed another parallel-diode with the current generator, in order to represent the rectifying behavior. The presence of the second diode prevented the recourse of the electrochemical variables, when the transfer of charges occurred at the paste. We schematically present the two-diode model in Figure 3. Applying the conservation of energy principal (via Kirchhoff equation), the characteristic equation of the circuit in Figure 3 can be described as

$$
\begin{aligned}
I= & I_{\mathrm{ph}}-I_{0-\text { For }}\left[\exp \left(\frac{q\left(V+I R_{s}\right)}{m_{\text {For }} k T}\right)-1\right] \\
& +I_{0-\text { rev }}\left[\exp \left(\frac{-q\left(V+I R_{s}\right)}{m_{\text {rev }} k T}\right)-1\right]-\frac{V+I R_{s}}{R_{\text {sh }}} .
\end{aligned}
$$

In dark conditions, it can be understood that, at reverse polarization, only the third term in (8) remained, while in the illumination conditions with forward polarization, the "one-diode" based model was equivalent to the two-diode based model. The values of $R_{s}$ were taken to be constant in our model, in both forward and reverse bias. As a first approximation, we considered $R_{s \text {-For }}=R_{s \text {-rev }}$ t that is, we considered the fact that they would have the same magnitude in both conditions. On the contrary, the physical meaning of the exponential term was controlled by the ideality-factor value, which depended on the operative conditions and was not equal. This means that the difference between the ideality factors in forward and reverse bias is a function of the condition of active working (temperature, illumination intensity, effective surface area, etc.).

\section{Results}

\subsection{Characterization of Obtained Cell}

4.1.1. Raman Scattering Spectra. At different excitation light, 514.5 nanometers, 676.4 nanometers, and 1064.0 nanometers, the main surface enhanced Raman scattering spectra characteristics of carbon nanotubes have been taken and are illustrated in Figure 4.

This figure shows characteristics of samples with different nanoropes of about 18 up to 99 separated CNTs which are in good agreement with published data [48]. As seen, the spectra of ropes are strongly depending on the excitation wavelength.

4.1.2. XPS Spectra. XPS spectra have been taken with SSX-100 ESCA spectrometer using $1486.6 \mathrm{eV}$ Al- $\mathrm{K}_{\alpha}$ radiation. Figure 5 illustrates XPS spectra with two different resolutions: (a) low

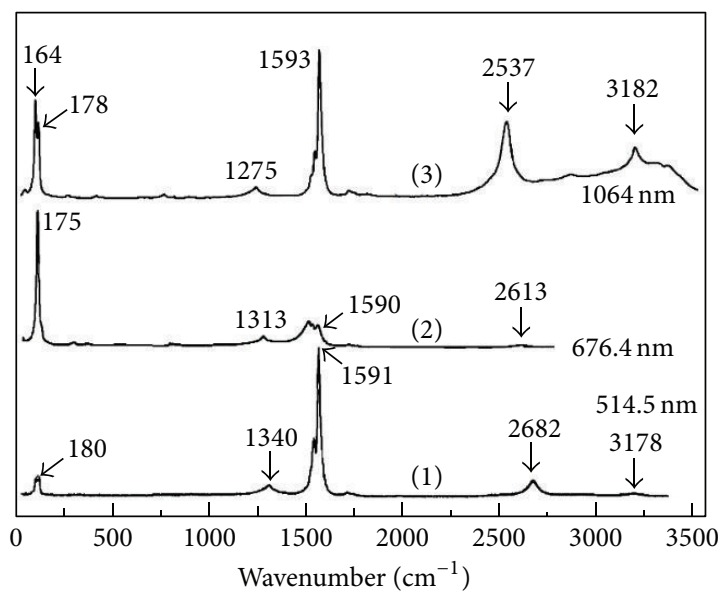

FIgURE 4: Surface enhanced Raman scattering spectra at different wave excitation lengths: (1) $\lambda_{1}=514.5 \mathrm{~nm}$, (1) (2) $\lambda_{2}=676.4 \mathrm{~nm}$, and (3) $\lambda_{3}=1064 \mathrm{~nm}$ of CNTs deposited on gold support.

and (b) high. The high resolution illustration shows the presence of C-C bond at $285 \mathrm{eV}$, in addition to some carbonyl moiety in harmony with carboxylated groups at $288 \mathrm{eV}$. The low-resolution XPS spectrum shows a net peak at $284.8 \mathrm{eV}$ which is due to carbon 1 s.

Mialhe et al. [49] and Ishibashi et al. [50] have shown that studying the effect of each variable on the different parts of the current-voltage curves (where some of these parameters could be neglected at certain parts of the $I-V$ characteristics) is the best way to understand the electrical behavior of the DSSCs. Models with one diode can be used to get an accurate estimation of the DSSCs physical parameters; that is, the application of (8) to the experimental data can give the cell parameters when extrapolating numerical calculations which could be obtained either from extrapolating experimental results [51] or from using the spectral and electrochemical studies with the help of a suitable equivalent circuit of DSSC (single cell). We carried out our analysis in two successive steps. First, an initial group of fitting parameters were extracted using experimental data; then, second, they were, iteratively, refined out using "Levenberg Marquardt," an algorithmic procedure that is used for nonlinear curve fitting [52]. In the analysis, we reported a detailed procedure for the estimation of the initial parameters:

(a) $I_{\mathrm{ph}}$ was considered to be coincident with the short circuit photocurrent, $I_{\mathrm{sc}}$.

(b) From the slope of current-voltage curves, we were able to estimate the shunt resistant $R_{\mathrm{sh}}$ when $I=I_{\mathrm{sc}}$ :

$$
-\left.\frac{d V}{d I}\right|_{I=I_{\mathrm{sc}}}=R_{\mathrm{sh}} .
$$

The value of $R_{\mathrm{sh}}$, in our device, was about $1.1 \times$ $10^{5} \Omega$, which was a remarkably high value. Accordingly, when we took into account the photocurrent values of about some milliamperes, then, we can consider $R_{\mathrm{sh}}$ to tend to infinite values. Moreover, O'Regan et al. [53] reported that rash usually 


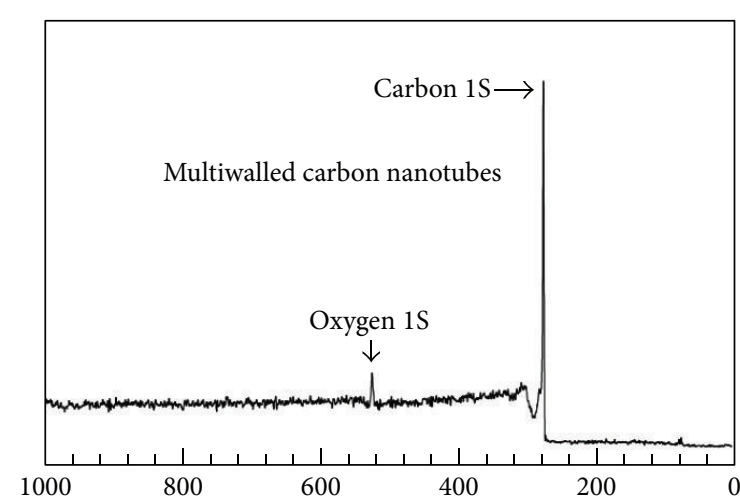

(a)

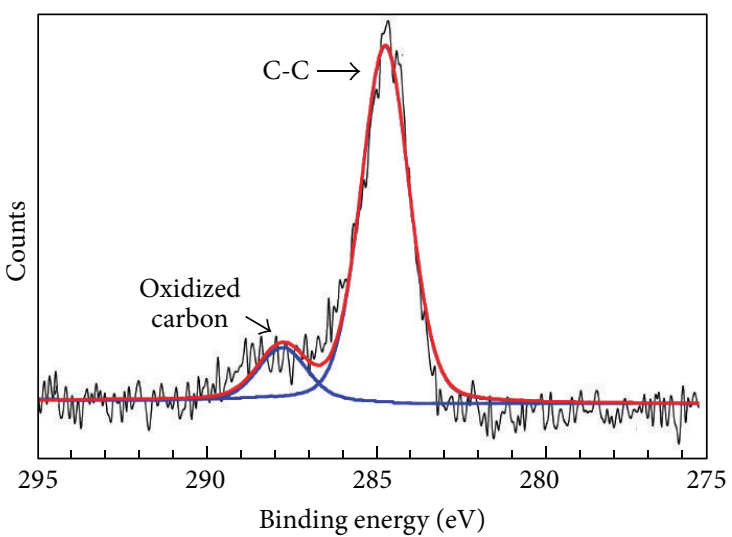

(b)

FIGURE 5: XPS spectra of carbon nanotubes (of C1s) with two different resolutions: (a) low and (b) high.

increased, when illumination decreased. Thus, we kept it as a constant factor.

(c) Following Han et al. [36], in forward bias, the series resistance $R_{s-F o r}$ could be obtained by direct application of the well known curves of $\varepsilon^{\prime}-\varepsilon^{\prime \prime}$ because of the addition of several different resistances: contact resistance, substrate sheet resistance, electrical resistance of the paste, and resistance of all wires of the cell.

(d) Then, we were able to estimate the exact potential through the cell $V_{F}$, by using the forward bias resistance, $R_{s-\text { For }}$ as

$$
V_{F}=V_{\text {appl }}-V_{s}=V_{\text {appl }}-I R_{s-\text { For }} \text {. }
$$

(e) The value of the recombination resistance was then estimated from the analysis of the different spectra of electrochemical impedance spectroscopy in the middle frequency region [42]:

$$
R_{\text {rec }}=\frac{k T}{q \beta I_{0-\text { For }}} \exp \left(\frac{-q \beta V_{F}}{k T}\right) .
$$

(f) We were able to estimate the value of the ideality factor in forward bias, using the semilog curve of the recombination resistance $R_{\text {rec }}$ versus the potential at the SC electrode, $V_{F}$, where $m_{\text {For }}=1 / \beta$ and $I_{0 \text {-For }}$.

With regard to the reverse-bias term in (8), the best fitting parameters of the current-voltage curves could be used to estimate several parameters of the DSSC: the reverse series resistance $R_{s-\text { rev }}$, the reverse series resistance $R_{s-\text { rev }}$, and the ideality factor $m_{\text {rev }}$. Here, one can easily neglect both $R_{s \text {-rev }}$ and the current generator.

(g) The value of recombination resistance is, then, estimated from analysis of the different spectra of electrochemical impedance spectroscopy in middle frequency region [42]:

$$
R_{\text {rec }}=\frac{k T}{q \beta I_{0-\text { For }}} \exp \left(\frac{-q \beta V_{F}}{k T}\right) .
$$

(h) The value of the ideality factor, in forward bias, could be estimated using semilog curve of recombination resistance $R_{\text {rec }}$ versus the potential at the SC electrode, $V_{F}$, where $m_{\text {For }}=1 / \beta$ and $I_{0 \text {-For }}$.

In regard to the reverse-bias term in (8), the best fitting parameters of current-voltage curves could be used to estimate several parameters of the DSSC: the reverse series resistance $R_{s \text {-rev }}$, the reverse series resistance $R_{s-\text { rev }}$, and the ideality factor $m_{\text {rev }}$. Here, one can easily neglect both $R_{s \text {-rev }}$ and the current generator.

At elevated negative voltages, with the best nonlinear square fitting processes, we estimated $I_{0}$ rev-values from its current value at zero voltage. Also, we found $R_{s \text {-rev }}$ from the slope of the current-voltage curves, particularly, at the straight line of the current-voltage curves. The initial value of $m_{\text {rev }}$ was considered as 1.5 , to be in the range $1<$ $m_{\text {rev }}<2$. Since we used the same series resistance, we assumed that $R_{s \text {-rev }}>R_{s \text {-For }}$. Systematically, the estimated $R_{s \text {-For }}$ was highly affected by the illumination intensity (or shadow rate). Figure 6 illustrates a steep decrease of the short circuit current with a shadowing rate. The open circuit voltage decreased also, at a high shadow rate, which could be predicted from (6). But a minor increase of the fill factor was as a result of the high shadow rate. We attributed this decrease of $R_{s}$ to the effect of photocurrent. The strong reduction in the $R_{s}$ value was a function of the produced photocurrent. The magnitudes of $R_{s \text {-For }}$, at 1 sun illumination, ranged as $20 \Omega$ (complete illumination) $<R_{s \text {-For }}<21 \Omega$ (0.75 of the complete illumination). Consequently, $R_{s \text {-For }}$ was nearly not affected by the extent of the shaded photovoltaic region, and the values of $R_{s \text {-For }}$ were taken as $R_{s \text {-rev }}$. Table 1 shows the information about the numerical coefficients.

To examine quantitatively the accuracy (including its validity) of our model for the different shadowing rates, we used "PSice" with the proposed model including the EC. By using this technique, the output power was accurately estimated after $I-V$ characteristics data. First, and for simplicity, at a complete shaded rate, we considered the module to be composed of only one single element, which would 
TABLE 2: Methods to estimate the numerical parameters used to fit experimental data to (8).

\begin{tabular}{lccccc}
\hline Symbol & $I_{\mathrm{ph}}$ & $I_{0}$ & $m$ & $R_{s}$ & $R_{\mathrm{sh}}$ \\
\hline Forward direction & $\approx I_{s}$ & Using EIS analysis & Using EIS & Using EIS & When $-\left.(d V / d I)\right|_{I=I_{\mathrm{sc}}}$ \\
Reverse direction & Using $(8)$ & Using (8) & Using (8) & Using $(8)$ & - \\
\hline
\end{tabular}

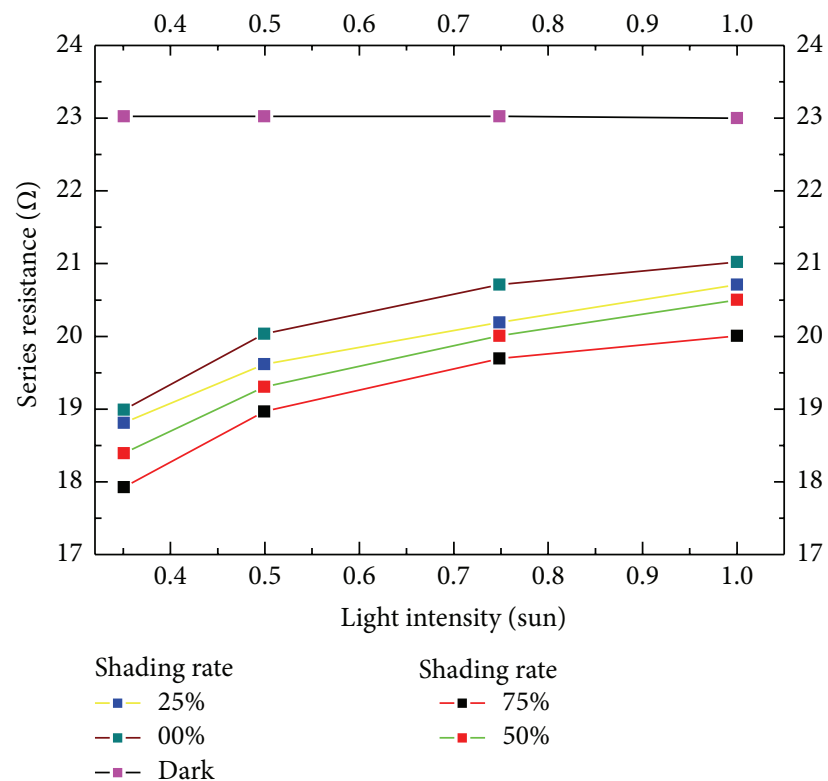

FIGURE 6: Series resistance as a function of light intensity for different shading rates.

overcome the recourse of analytical expressions. Then, we estimated the module with several elements of each solar cell, by looking for the best parameters that fit well (see (8)) with the experimental results at different rates of shadow. Fitted and experimental $I-V$ characteristics data are reported in Figure 7 with a completely shaded cell. Because a shaded cell tends to behave in reverse bias, the data demonstrated that the reverse diode was "turned on."

The potential that was just adequate to make the difference between the open circuit voltages of the module greater than the open circuit voltage of the shaded solar cell occurred when switching on the reverse diode. This reverse voltage $V_{\text {rev }}$ stimulated the current to pass in a reverse direction, and this converted the cell into an electric resistor instead of being a current generator. The diminution of the potential ( $\left.V_{\text {bump }}\right)$ can be estimated as

$$
V_{\text {bump }}=V_{\text {OC }}+V_{\text {rev }} \text {. }
$$

One can estimate $V_{\text {OC }}$ directly by using (6), and $V_{\text {rev }}$ was calculated, taking into consideration the parameters illustrated in Figure 6:

$$
V_{\text {rev }}=\frac{k T}{q m_{\text {rev }}} \ln \left(\frac{I_{\mathrm{ph}}}{I_{0-\mathrm{rev}}}\right)
$$

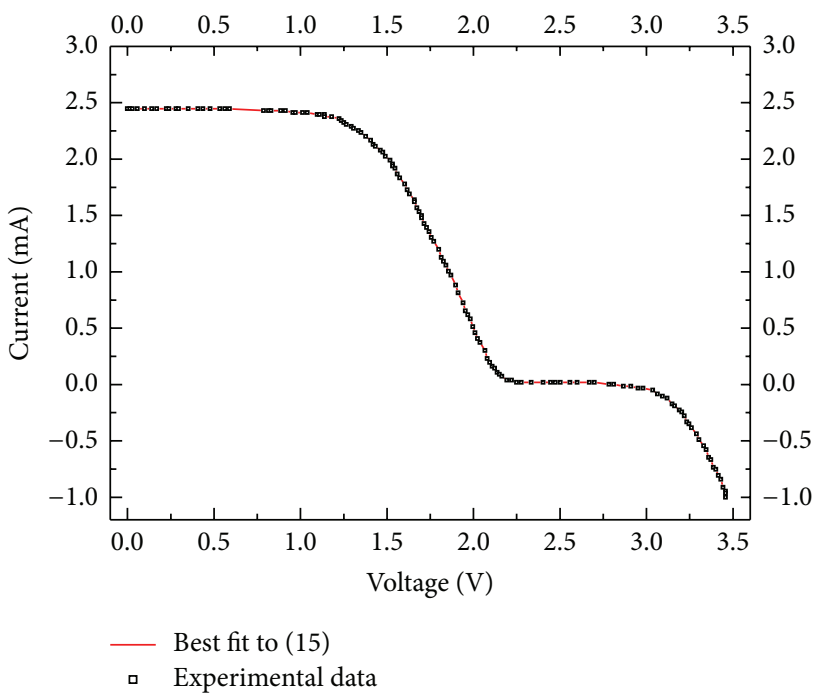

FIgURE 7: Experimental data of $I-V$ characteristics of a four-cell module with one fully shadowed cell.

Table 2 shows the magnitudes of the physical parameters which have best fitted the experimental data to the model.

Using the principal of charge conservation, Sastrawan et al. [44] derived an expression that described the $I-V$ characteristics of the cell in forward bias; their fitting values were not very far from ours, whereas the BVM ((7)) explained the reverse-biased behavior conduction in DSSC. One writes

$$
\begin{aligned}
I= & I_{\mathrm{ph}} I_{\mathrm{rr}} \beta-A \frac{q D n_{0} d}{L^{2}}\left[\exp \left(\frac{q\left(V+I R_{s}\right)}{m_{\mathrm{For}} k T}\right)-1\right] \beta \\
& -A j_{0}\left[\exp \left(\frac{\alpha n\left(V+I R_{s}\right)}{k T}\right)\right. \\
& \left.-\exp \left(\frac{-(1-\alpha) n\left(V+I R_{s}\right)}{k T}\right)\right]-\left(\frac{V+I R_{s}}{R_{\mathrm{sh}}}\right) .
\end{aligned}
$$

$I_{\mathrm{ph}}$ is the photocurrent, $I_{\mathrm{rr}}$ is the constant correlated with the irradiance parameter, $\beta$ is the shadowing rate, $D$ is the diffusion length of the electron, $j_{0}$ is the exchange current density, $\alpha$ is the cathodic transfer coefficient, $n$ is the number of electrons transferred, and $A$ is the surface of the area cell.

Equation (15) could be approximated, in reverse bias, where the first quantity could be neglected, but the second quantity has no real effect on the current density in the forward bias. The different physical parameters, described by (14), of the DSSC are reported in Table 3. Noting that $I_{\mathrm{ph}}$ is taken to be coincident with $I_{\mathrm{sc}}$, just like Halm et al. [42], 
TABLE 3: Best fitting parameters and experimental values to fit experimental data to $(8)$.

\begin{tabular}{lccc}
\hline Symbol & Parameter & Value & Units \\
\hline$I_{\text {sc }}$ & $\begin{array}{c}\text { Short circuit } \\
\text { current }\end{array}$ & 2.4 & $\mathrm{~mA}$ \\
$R_{\mathrm{s} \text {-For }}$ & Series resistance & 20 & $\Omega$ \\
$R_{\mathrm{s} \text {-rev }}$ & Series resistance & 23 & $\Omega$ \\
$I_{0 \text {-rev }}$ & Irradiance factor & $2.3 \times 10^{-5}$ & $\mathrm{~mA}$ \\
$d$ & Film thickness & $7 \times 10^{-6}$ & $\mathrm{~m}$ \\
$m_{\text {rev }}$ & Diode ideality & 1.1 & - \\
& $\quad$ factor & 1.5 & - \\
$m_{\text {For }}$ & Diode ideality & factor & \\
$A$ & Area of dye & 0.28 & $\mathrm{~cm}^{2}$ \\
$T$ & sensitized solar cell & 300 & $\mathrm{~K}$ \\
\hline
\end{tabular}

we have used the following equations to deduce the values of $D$ and $L$ :

$$
\begin{aligned}
& D=\frac{d^{2}}{R_{T} C_{\mu}}, \\
& \tau=R_{\mathrm{rec}} C_{\mu}, \\
& L=\sqrt{D \tau}=d \sqrt{\frac{R_{\mathrm{rec}}}{R_{\mathrm{CT}}}} .
\end{aligned}
$$

Moreover, just like Sastrawan et al. [44], we have calculated the cathodic transfer coefficient $\alpha$ and we have, also, used the work of Van De Lagemaat and Frank [52], to estimate the electron density, $n_{0}$.

Figure 7 shows the electrical behavior of the conduction mechanism, which is a direct reflection of (15). However, the fit between the experimental data and model is not quite well demonstrated. This is because one has used the single independent measurements, to describe different physical parameters; so, some of the cell parameters have to be kept constant at certain conditions. For example, Wang et al. [54] have shown that the diffusion length $L$ depends on the potential. The fitting parameters $\beta$ and $I_{\text {rr }}$ could be estimated, when varying the shadowing conditions of the cell. The simulated curve estimated after (8) fits the experimental data well. Thus, our model allows us to predict the values of the recombination rates (current), by following the interface between the paste and the transparent conductive oxide layer, which leads to a corresponding potential decrease, due to photovoltage drop $V_{\text {bump }}$. Figure 8 shows the measured and simulated current-voltage curves with the complete shadowing rate.

The presented model (two-diode model) fits well for all the 4 shadowing rates, which are seen from the simulation plots. The value of $V_{\text {bump }}$ is doubled, when comparing it with a single cell. This is well shown after (13), when all the parameters are doubled. Similar electric results are shown with a complete shadowing rate, and with a multiplication factor of 3. This explanation is only applied, when the

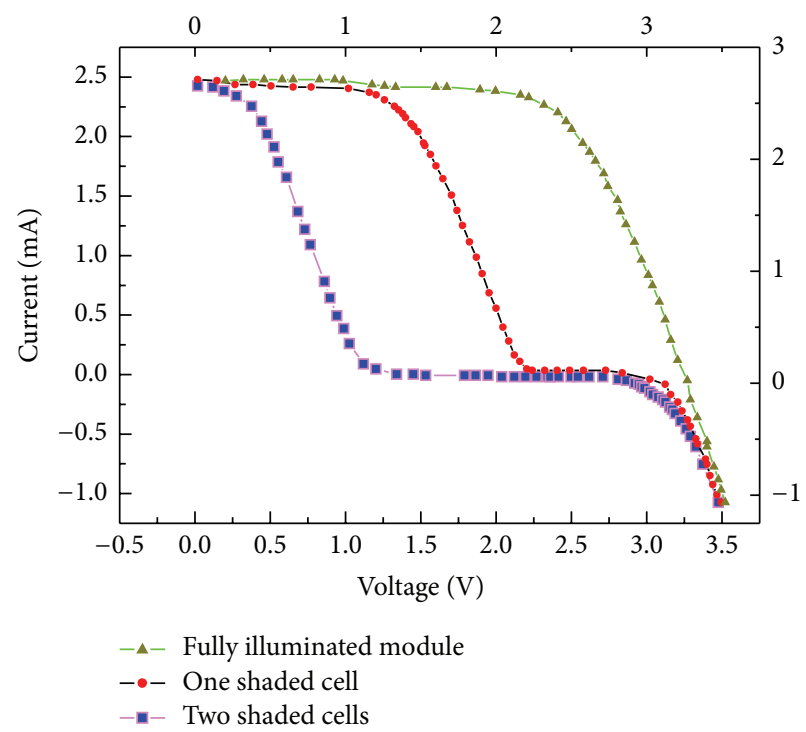

FIGURE 8: $I$ - $V$ characteristics experimental data for different shading rates illustrated as symbols and one shaded cell, two shaded cells, and fully illuminated module.

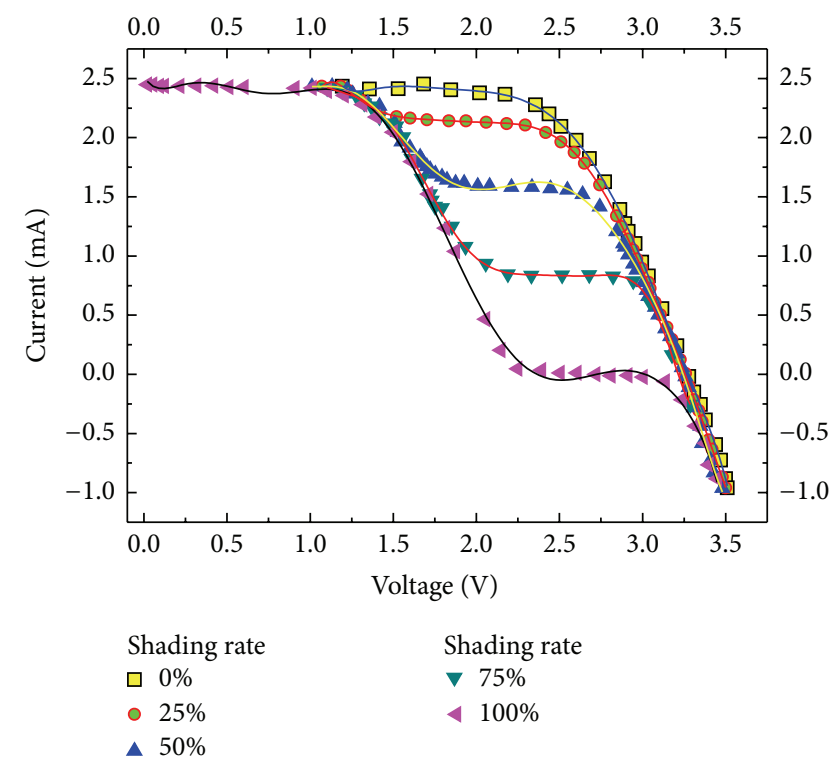

FIGURE 9: $I-V$ characteristics experimental data for different shading rates illustrated as symbols.

four elements composed of cells with different electrical parameters, $V_{\text {rev }}$ and $V_{\text {OC }}$, are determined for all the cells with different shadow rates which makes it possible to put the second term in (13) as a sum product.

Figure 9 shows that good simulation plots obtained when considering a two-diode model fit nearly perfectly for all the experimental current-voltage curves. In this figure, the simulation plots obtained by application of a 2-diode model fit nearly perfectly to the experimental data concerning all the considered shadowing rates. The reverse current passing the diode will induce the DSSC to operate as a load under potentials over 1.45 volts, if only one quart of the effective surface of 
the photoelectrode is put in the dark. Consequently, the step is added to the $I-V$ characteristics because the reverse diode is turned on suddenly. When half of the active area is shaded, the electric current arising from recombination increases more than the current generated by the photoexcitation at the unshaded photoelectrode; thus, the net output current will decrease which is shown by a plateau when reaching the critical short circuit value of the shaded cell, keeping the value of $V_{\text {bump }}$ constant. The $x$-axis extension of the area lies under the influence of the photocurrent drop $V_{\text {bump }}$, and it does not get affected by the factor relating the illuminating active area of the photoelectrode to the obscured one as it is expected from (13).

When half of the active area is shaded, the electric current arising from recombination increases more than the current generated by the photoexcitation at the unshaded photoelectrode electrode; thus, the net output current will decrease which is shown by a plateau when reaching the critical short circuit value of the shaded cell, keeping the value of $V_{\text {bump }}$ constant. The $x$-axis extension of the area lying under the influence of the photocurrent drop $V_{\text {bump }}$ does not get affected by the factor relating illuminating active area of the photoelectrode to the obscured one as it is expected from (13). The carbon nanotubes in the present study were doublewalled which are conductive materials. They can reduce the contact resistance which decreases in turn the charge transfer $R_{\mathrm{CT}}$ resistance with the DSSC due to fast transfer kinetics of electric charges (Table 4 ).

Lee et al. [55] have used carbon nanotubes as counter electrodes in DSSC and found a photovoltaic efficiency of $7.67 \%$ and the values of $R_{\mathrm{CT}}$ of their cell were $0.82 \mathrm{ohms} \mathrm{cm}^{2}$. Interestingly, their efficiency is comparable to the typical Pt-DSSC photovoltaic efficiency (7.83\%). Experimental measurements of the present work have led to an efficiency of $5.7 \%$ and one can attribute the low value of efficiency to the nature of the impurities in the commercial carbon nanotubes and the effect of defect-rich edge planes in the bamboostructured carbon nanotubes.

In addition, the measurements data of the present work have given relatively low values of the charge transfer resistance, about $1.05 \mathrm{ohms} \mathrm{cm}^{2}$ which is lower than that of typical Pt-electrode $\left(1.8 \mathrm{ohms} \mathrm{cm}^{2}\right)$. Our data are summarized in Table 5.

The function of DSSC is very sensitive to the number of walls of carbon nanotubes. In general, these nanotubes can be classified into single-walled carbon nanotubes, doublewalled carbon nanotubes, and multiwalled carbon nanotubes. Zhang et al. [56] have compared the photovoltaic efficiency of three different DSSCs based on single-walled carbon nanotubes, double-walled carbon nanotubes, and multiwalled carbon nanotubes. They have found that the efficiencies vary in the range, $8.03 \%$ for double-walled carbon nanotubes, $7.61 \%$ for single-walled carbon nanotubes, and $7.06 \%$ for multiwalled carbon nanotubes. These efficiencies have been well matched with the charge transfer resistance; that is, $R_{\mathrm{CT}}=3.13 \mathrm{ohms} \mathrm{cm}^{2}$ for double-walled carbon nanotubes, $R_{\mathrm{CT}}=6.72 \mathrm{ohms} \mathrm{cm}$ for single-walled carbon nanotubes, and $R_{\mathrm{CT}}=10$ for multiwalled carbon nanotubes.
TABLE 4: Best fitting parameters and experimental values to fit experimental data to (15).

\begin{tabular}{|c|c|c|c|}
\hline Symbol & Parameter & Value & Units \\
\hline$R_{\mathrm{sh}}$ & Shunt resistance & $1.1 \times 10^{5}$ & $\Omega$ \\
\hline$R_{s}$ & Series resistance & 20 & $\Omega$ \\
\hline$I_{n}$ & Irradiance factor & $0<I_{n}<1$ & - \\
\hline$I_{\mathrm{ph}}$ & Short circuit current & 2.435 & $\mathrm{~mA}$ \\
\hline$d$ & Film thickness & $7 \times 10^{-6}$ & $\mathrm{~m}$ \\
\hline$\beta$ & $\begin{array}{l}\text { Shadow's } \\
\text { transmittance factor }\end{array}$ & $0<\beta<1$ & - \\
\hline$D$ & $\begin{array}{l}\text { Electron diffusion } \\
\text { coefficient }\end{array}$ & $5.2 \times 10^{-5}$ & $\mathrm{~cm}^{2} \mathrm{~s}^{-1}$ \\
\hline$n_{0}$ & $\begin{array}{l}\text { Electron density in } \\
\text { the dark }\end{array}$ & $1 \times 10^{7}$ & $\mathrm{~cm}^{-3}$ \\
\hline$D$ & $\begin{array}{l}\text { Electron diffusion } \\
\text { length }\end{array}$ & $24.5 \times 10^{-6}$ & $\mathrm{~m}$ \\
\hline$j_{0}$ & $\begin{array}{c}\text { Exchange current } \\
\text { density }\end{array}$ & $7 \times 10^{-8}$ & $\mathrm{~mA} \mathrm{~cm}^{-2}$ \\
\hline$\alpha$ & $\begin{array}{l}\text { Cathodic transfer } \\
\text { coefficient }\end{array}$ & 0.35 & - \\
\hline$n$ & Electrons transferred & 1 & - \\
\hline$m$ & Diode ideality factor & 1.5 & - \\
\hline$A$ & $\begin{array}{c}\text { Area of dye sensitized } \\
\text { solar cell }\end{array}$ & 0.28 & $\mathrm{~cm}^{2}$ \\
\hline$T$ & Temperature & 300 & $\mathrm{~K}$ \\
\hline
\end{tabular}

The double-walled carbon nanotubes have larger "inner surface area" that can easily activate the charge transfer between them. However, the bamboo structure of multiwalled carbon nanotubes has more complicated "inner surface area" that strongly decrease the charge mobility and increase the corresponding charge transfer resistance. Consequently, this decreases the photovoltaic efficiency.

Carbon nanofibers have large surface area, high density of surface defects, and very thin filament size. These characteristics lead to an efficient DSSC due to their thinner thickness. As is well known, the electrical resistance of the counter electrode decreases as it gets thinner: Electrical resistance $(R)=$ resistivity $(\rho) *$ length $(l) /$ area $(A)$. For example, as the counter electrode increases from 5 micrometers, 10 micrometers, and 15 micrometers, to 20 micrometers, the net DSSC series resistance increases from $6.9 \mathrm{ohms} \mathrm{cm}$, $9.9 \mathrm{ohms} \mathrm{cm} \mathrm{cm}^{2}, 10.6 \mathrm{ohms} \mathrm{cm}$, and $11.9 \mathrm{ohms} \mathrm{\textrm {cm } ^ { 2 }}$. Because all factors are constant and only the counter electrode thickness decreases with the carbon nanofibers structure, the overall efficiency of DSSC with carbon nanofiber increases as a result of the reduction of counter electrode area. Table 6 shows the photovoltaic efficiency as a function of counter electrode thickness.

Comparing the experimental data recently published by Elbohy et al. [57] to the typical Pt- counter electrodes or carbon nanotubes counter electrodes, the carbon fiber SDDC has higher electrocatalytic efficiency and photovoltaic performance. This is attributed to its low electrical resistance of charge transfer and to high interfacial area. This also leads to accelerating mobility of charges which will reduce 
TABLE 5: Current-voltage characteristics of DSSC with carbon nanotubes as counter electrode: measurements have been carried out under 0.75 sun illumination.

\begin{tabular}{lccccc}
\hline Counter electrode & $\begin{array}{c}R_{\mathrm{CT}}\left(\mathrm{ohms} \mathrm{cm}^{2}\right) \\
\pm 0.4\end{array}$ & $j_{\mathrm{SC}}\left(\mathrm{mA} \mathrm{cm}^{2}\right) \pm 0.1$ & $V_{\mathrm{OC}}, \pm 0.04$ volt & FF \pm 0.02 & Efficiency\% \pm 0.2 \\
\hline CNTs & 1.05 & 8.2 & 0.32 & 0.32 & 5.7 \\
Pt & 1.8 & 13.4 & 0.81 & 0.64 & 6.9 \\
Bare FTO & - & 1.7 & 0.82 & 0.04 & 0.06 \\
\hline
\end{tabular}

$R_{\mathrm{CT}}$ : charge transfer resistance, $j_{\mathrm{SC}}$ : short circuit current, $V_{\mathrm{OC}}$ : open circuit voltage, and FF: fill factor. Active area of the device is $0.25 \mathrm{~cm}^{2}$.

TABLE 6: DSSC parameters as a function of counter electrode thickness.

\begin{tabular}{|c|c|c|c|c|c|}
\hline Thickness, $\mu \mathrm{m}$ & $R_{\mathrm{CT}}\left(\mathrm{ohms} \mathrm{\textrm {cm } ^ { 2 } )}\right.$ & $j_{\mathrm{SC}}\left(\mathrm{mAcm}^{2}\right)$ & $V_{\mathrm{OC}}$, volt & $\mathrm{FF} \pm 0.02$ & Efficiency\% \\
\hline 5 & 6.9 & $18.7 \pm 0.1$ & $0.78 \pm 0.007$ & 67 & $9.77 \pm 0.14$ \\
\hline 10 & 9.9 & $18.41 \pm 0.12$ & $0.78 \pm 0.005$ & 63 & $9.05 \pm 0.12$ \\
\hline 15 & 10.6 & $17.837 \pm 0.18$ & $0.78 \pm 0.005$ & 60 & $8.34 \pm 0.14$ \\
\hline 20 & 11.9 & $17.1 \pm 0.1$ & $0.78 \pm 0.005$ & 57 & $7.63 \pm 0.09$ \\
\hline
\end{tabular}

the rate of reduction and increases the performance. More studies of counter electrode thickness and charge transfer resistance will give huge steps to improving the efficiency of solar conversion.

\section{Conclusions}

It has been demonstrated that the addition of a second diode to the equivalent circuit explains quite well the reverse behavior of the shaded elements; and this addition fits well the forward bias $I-V$ characteristics of the experimental data, when working in several shading conditions. It has, also, been shown that different rates of shadow affect the efficiency of a dye synthesized solar cell. When applying the 2-diode model, we found very close matching between the experimental values of $I-V$ curves and the simulation data. Our approaches used a few amounts of fitting factors compared to the previously proposed models, which makes this model relatively flexible, effective, and more reliable.

\section{Conflict of Interests}

The authors declare that there is no conflict of interests regarding the publication of this paper.

\section{Acknowledgments}

This project was funded by the Deanship of Scientific Research (DSR), King Abdulaziz University, Jeddah, under Grant no. G-1436-130-35. The authors, therefore, acknowledge with thanks DSR technical and financial support.

\section{References}

[1] M. Grätzel, "Solar energy conversion by dye-sensitized photovoltaic cells," Inorganic Chemistry, vol. 44, no. 20, pp. 6841-6851, 2005.

[2] B. O'Regan and M. Grätzel, "Low-cost, high-efficiency solar cell based on dye-sensitized colloidal $\mathrm{TiO}_{2}$ films," Nature, vol. 353, no. 6346 , pp. 737-740, 1991.
[3] U. Mehmood, S.-U. Rahman, K. Harrabi, I. A. Hussein, and B. V. S. Reddy, "Recent advances in dye sensitized solar cells," Advances in Materials Science and Engineering, vol. 2014, Article ID 974782, 12 pages, 2014.

[4] A. V. Shah, H. Schade, M. Vanecek et al., "Thin-film silicon solar cell technology," Progress in Photovoltaics: Research and Applications, vol. 12, no. 2-3, pp. 113-142, 2004.

[5] K. Chopra, P. Paulson, and V. Dutta, "Thin-film solar cells: an overview," Progress in Photovoltaics: Research and Applications, vol. 12, pp. 69-92, 2004.

[6] M. Grätzel, "Dye-sensitized solar cells," Journal of Photochemistry and Photobiology C: Photochemistry Reviews, vol. 4, no. 2, pp. 145-153, 2003.

[7] A. Hagfeldt and M. Grätzel, "Molecular photovoltaics," Accounts of Chemical Research, vol. 33, no. 5, pp. 269-277, 2000.

[8] H. Hoppe and N. S. Sariciftci, "Organic solar cells: an overview," Journal of Materials Research, vol. 19, no. 7, pp. 1924-1945, 2004.

[9] N. Robertson, "Optimizing dyes for dye-sensitized solar cells," Angewandte Chemie-International Edition, vol. 45, no. 15, pp. 2338-2345, 2006.

[10] L. Schmidt-Mende, U. Bach, R. Humphry-Baker et al., "Organic dye for highly efficient solid-state dye-sensitized solar cells," Advanced Materials, vol. 17, no. 7, pp. 813-815, 2005.

[11] D. B. Kuang, S. Ito, B. Wenger et al., "High molar extinction coefficient heteroleptic ruthenium complexes for thin film dyesensitized solar cells," Journal of the American Chemical Society, vol. 128, no. 12, pp. 4146-4154, 2006.

[12] J. B. Baxter and E. S. Aydil, "Nanowire-based dye-sensitized solar cells," Applied Physics Letters, vol. 86, no. 5, Article ID 053114, 2005.

[13] M. Law, L. E. Greene, J. C. Johnson, R. Saykally, and P. Yang, "Nanowire dye-sensitized solar cells," Nature Materials, vol. 4, no. 6, pp. 455-459, 2005.

[14] M. R. Karim, A. Islam, M. D. Akhtaruzzaman, L. Han, and A. Al-Ahmari, "Multiwall carbon nanotube coated with conducting polyaniline nanocomposites for quasi-solid-state dyesensitized solar cells," Journal of Chemistry, vol. 2013, Article ID 962387, 5 pages, 2013.

[15] K. T. Dembele, R. Nechache, L. Nikolova et al., "Effect of multiwalled carbon nanotubes on the stability of dye sensitized solar cells," Journal of Power Sources, vol. 233, pp. 93-97, 2013. 
[16] J. Balamurugan, R. Thangamuthu, and A. Pandurangan, "Growth of carbon nanotubes over transition metal loaded on Co-SBA-15 and its application for high performance dyesensitized solar cells," Journal of Materials Chemistry A, vol. 1, no. 16, pp. 5070-5080, 2013.

[17] S. Chen, J. Weng, Y. Huang et al., "Numerical model analysis of the shaded dye-sensitized solar cell module," Journal of Physics D: Applied Physics, vol. 43, no. 30, Article ID 305102, 2010.

[18] L. De Marco, M. Manca, R. Giannuzzi et al., "Novel preparation method of $\mathrm{TiO}_{2}$-nanorod-based photoelectrodes for dyesensitized solar cells with improved light-harvesting efficiency," Journal of Physical Chemistry C, vol. 114, no. 9, pp. 4228-4236, 2010.

[19] J. C. Slonczewski and P. R. Weiss, "Band structure of graphite," Physical Review, vol. 109, no. 2, pp. 272-279, 1958.

[20] X. Wu, F. Li, W. Wu, and T. Guo, "Flexible white phosphorescent organic light emitting diodes based on multilayered graphene/PEDOT:PSS transparent conducting film," Applied Surface Science, vol. 295, pp. 214-218, 2014.

[21] K. Aitola, A. Kaskela, J. Halme et al., "Single-walled carbon nanotube thin-film counter electrodes for indium tin oxide-free plastic dye solar cells," Journal of the Electrochemical Society, vol. 157, no. 12, pp. B1831-B1837, 2010.

[22] M. S. Akhtar, Z. Y. Li, D. M. Park, D. W. Oh, D.-H. Kwak, and O.-B. Yang, "A new carbon nanotubes (CNTs)-poly acrylonitrile (PAN) composite electrolyte for solid state dye sensitized solar cells," Electrochimica Acta, vol. 56, no. 27, pp. 9973-9979, 2011.

[23] M. Batmunkh, M. J. Biggs, and J. G. Shapter, "Carbonaceous dye-sensitized solar cell photoelectrodes," Advanced Science, vol. 2, no. 3, 2015.

[24] X. Zheng, J. Deng, N. Wang et al., "Podlike N-doped carbon nanotubes encapsulating FeNi alloy nanoparticles: highperformance counter electrode materials for dye-sensitized solar cells," Angewandte Chemie-International Edition, vol. 53, no. 27, pp. 7023-7027, 2014.

[25] C. K. Hong, H. S. Ko, E. M. Han, and K. H. Park, "Electrochemical properties of electrodeposited PEDOT counter electrode for dye-sensitized solar cells," International Journal of Electrochemical Science, vol. 10, pp. 5521-5529, 2015.

[26] A. G. Nasibulin, A. Kaskela, K. Mustonen et al., "Multifunctional free-standing single-walled carbon nanotube films," ACS Nano, vol. 5, no. 4, pp. 3214-3221, 2011.

[27] C. Feng, K. Liu, J.-S. Wu et al., "Flexible, stretchable, transparent conducting films made from superaligned carbon nanotubes," Advanced Functional Materials, vol. 20, no. 6, pp. 885-891, 2010.

[28] L. Hu, G. Grüner, M. W. Rowell et al., "Organic solar cells with carbon nanotube network electrodes," Applied Physics Letters, vol. 88, Article ID 233506, 2006.

[29] F. Mirri, A. W. K. Ma, T. T. Hsu et al., "High-performance carbon nanotube transparent conductive films by scalable dip coating," ACS Nano, vol. 6, no. 11, pp. 9737-9744, 2012.

[30] J. W. Jo, J. W. Jung, J. U. Lee, and W. H. Jo, "Fabrication of highly conductive and transparent thin films from single-walled carbon nanotubes using a new non-ionic surfactant via spin coating," ACS Nano, vol. 4, no. 9, pp. 5382-5388, 2010.

[31] S. Kim, J. Yim, X. Wang, D. D. C. Bradley, S. Lee, and J. C. DeMello, "Spin-and spray-deposited single-walled carbonnanotube electrodes for organic solar cells," Advanced Functional Materials, vol. 20, no. 14, pp. 2310-2316, 2010.

[32] M. D. Lima, M. J. de Andrade, C. P. Bergmann, and S. Roth, "Thin, conductive, carbon nanotube networks over transparent substrates by electrophoretic deposition," Journal of Materials Chemistry, vol. 18, no. 7, pp. 776-779, 2008.

[33] B. Dan, G. C. Irvin, and M. Pasquali, "Continuous and scalable fabrication of transparent conducting carbon nanotube films," ACS Nano, vol. 3, no. 4, pp. 835-843, 2009.

[34] D.-Y. Cho, K. Eun, S.-H. Choa, and H.-K. Kim, "Highly flexible and stretchable carbon nanotube network electrodes prepared by simple brush painting for cost-effective flexible organic solar cells," Carbon, vol. 66, pp. 530-538, 2014.

[35] I. Chung, B. Lee, J. He, R. P. H. Chang, and M. G. Kanatzidis, "All-solid-state dye-sensitized solar cells with high efficiency," Nature, vol. 485, no. 7399, pp. 486-489, 2012.

[36] L. Han, N. Koide, Y. Chiba, A. Islam, and T. Mitate, "Modeling of an equivalent circuit for dye-sensitized solar cells: improvement of efficiency of dye-sensitized solar cells by reducing internal resistance," Comptes Rendus Chimie, vol. 9, no. 5-6, pp. 645-651, 2006.

[37] A. Marchioro, J. Teuscher, D. Friedrich et al., "Unravelling the mechanism of photoinduced charge transfer processes in lead iodide perovskite solar cells," Nature Photonics, vol. 8, no. 3, pp. 250-255, 2014.

[38] B. O’Regan, J. Moser, M. Anderson, and M. Grätzel, "Vectorial electron injection into transparent semiconductor membranes and electric field effects on the dynamics of light-induced charge separation," Journal of Physical Chemistry, vol. 94, no. 24, pp. 8720-8726, 1990.

[39] M. Grätzel, Heterogeneous Photochemical Electron Transfer, vol. 89, CRC Press, Boca Raton, Fla, USA, 1989.

[40] S. Sodergern, A. Hagfeldt, J. Olsson, and S. Lindquist, "Theoretical models for the action spectrum and the currentvoltage characteristics of microporous semiconductor films in photoelectrochemical cells," The Journal of Physical Chemistry, vol. 98, no. 21, pp. 5552-5556, 1994.

[41] M. Bashahu and P. Nkundabakura, "Review and tests of methods for the determination of the solar cell junction ideality factors," Solar Energy, vol. 81, no. 7, pp. 856-863, 2007.

[42] J. Halm, P. Vaherma, K. Miettunen, and P. Lund, "Device physics of dye solar cells," Advanced Materials, vol. 22, no. 35, pp. E210E234, 2010.

[43] E. M. Barea, C. Zafer, B. Gultekin et al., "Quantification of the effects of recombination and injection in the performance of dye-sensitized solar cells based on $N$-substituted carbazole dyes," Journal of Physical Chemistry C, vol. 114, no. 46, pp. 1984019848, 2010.

[44] R. Sastrawan, J. Renz, C. Prahl, J. Beier, A. Hinsch, and R. Kern, "Interconnecting dye solar cells in modules- $I-V$ characteristics under reverse bias," Journal of Photochemistry and Photobiology A: Chemistry, vol. 178, no. 1, pp. 33-40, 2006.

[45] M. Wolf and H. Rauschenbach, "Series resistance effects on solar cell measurements," Advanced Energy Conversion, vol. 3, no. 2, pp. 455-479, 1963.

[46] A. Hauch and A. Georg, "Diffusion in the electrolyte and charge-transfer reaction at the platinum electrode in dyesensitized solar cells," Electrochimica Acta, vol. 46, no. 22, pp. 3457-3466, 2001.

[47] P. J. Cameron, L. M. Peter, S. M. Zakeeruddin, and M. Grätzel, "Electrochemical studies of the $\mathrm{Co}(\mathrm{III}) / \mathrm{Co}(\mathrm{II})(\mathrm{dbbip})_{2}$ redox couple as a mediator for dye-sensitized nanocrystalline solar cells," Coordination Chemistry Reviews, vol. 248, no. 13-14, pp. 1447-1453, 2004.

[48] A. Thess, R. Lee, P. Nikolaev et al., "Crystalline ropes of metallic carbon nanotubes," Science, vol. 273, no. 5274, pp. 483-487, 1996. 
[49] P. Mialhe, A. Khoury, and J. P. Charles, "A review of techniques to determine the series resistance of solar cells," Physica Status Solidi (A), vol. 83, no. 1, pp. 403-409, 1984.

[50] K.-I. Ishibashi, Y. Kimura, and M. Niwano, "An extensively valid and stable method for derivation of all parameters of a solar cell from a single current voltage characteristic," Journal of Applied Physics, vol. 103, no. 9, Article ID 094507, 2008.

[51] K. Levenberg, "A method for the solution of certain non-linear problems in least squares," Quarterly of Applied Mathematics, vol. 2, pp. 164-168, 1944.

[52] J. Van De Lagemaat and A. J. Frank, "Effect of the surfacestate distribution on electron transport in dye-sensitized $\mathrm{TiO}_{2}$ solar cells: nonlinear electron-transport kinetics," The Journal of Physical Chemistry B, vol. 104, no. 18, pp. 4292-4294, 2000.

[53] B. O’Regan, F. Lenzmann, R. Muis, and J. Wienke, "A solid-state dye-sensitized solar cell fabricated with pressure-treated $\mathrm{P}_{2} 5$ $\mathrm{TiO}_{2}$ and CuSCN: analysis of pore filling and IV characteristics," Chemistry of Materials, vol. 14, no. 12, pp. 5023-5029, 2002.

[54] Q. Wang, S. Ito, M. Grätzel et al., "Characteristics of high efficiency dye-sensitized solar cells," The Journal of Physical Chemistry B, vol. 110, no. 50, pp. 25210-25221, 2006.

[55] W. J. Lee, E. Ramasamy, D. Y. Lee, and J. S. Song, "Efficient dyesensitized solar cells with catalytic multiwall carbon nanotube counter electrodes," ACS Applied Materials and Interfaces, vol. 1, no. 6, pp. 1145-1149, 2009.

[56] D. Zhang, X. Li, S. Chen, Z. Sun, X. J. Yin, and S. Huang, "Performance of dye-sensitized solar cells with various carbon nanotube counter electrodes," Microchimica Acta, vol. 174, no. 1-2, pp. 73-79, 2011.

[57] H. Elbohy, A. Aboagye, S. Sigdel et al., "Graphene-embedded carbon nanofibers decorated with Pt nanoneedles for high efficiency dye-sensitized solar cells," Journal of Materials Chemistry A, vol. 3, no. 34, pp. 17721-17727, 2015. 

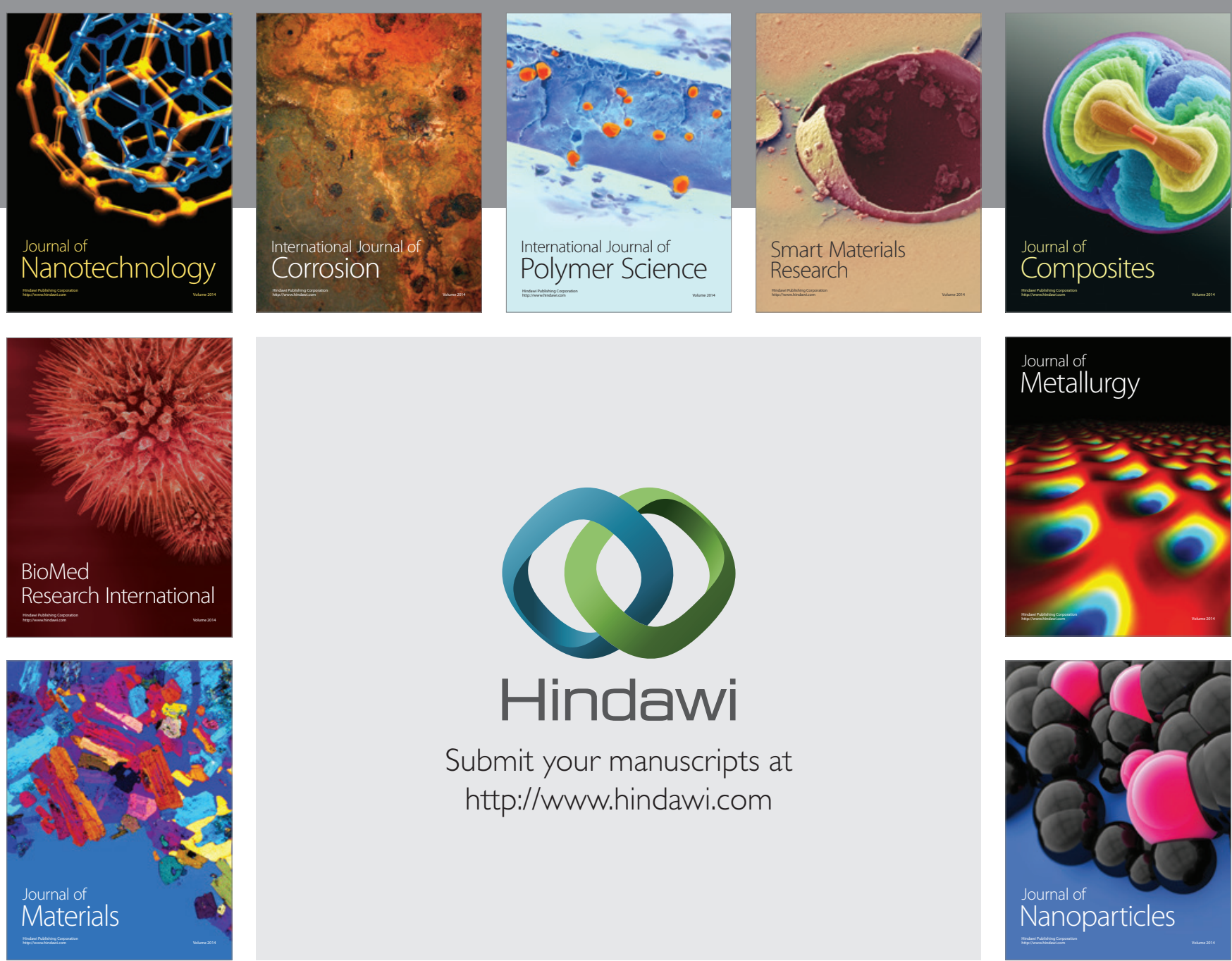

\section{Hindawi}

Submit your manuscripts at

http://www.hindawi.com

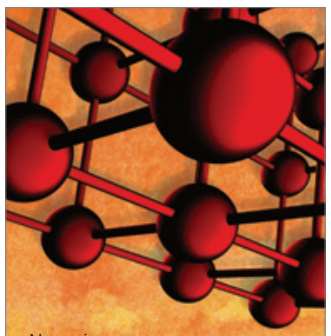

Materials Science and Engineering
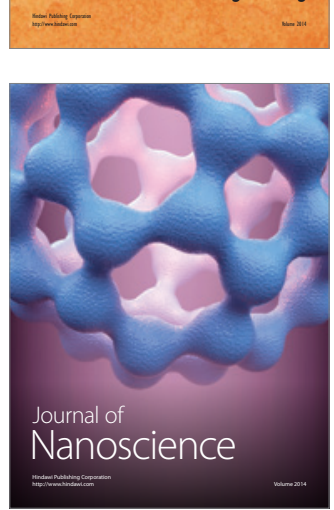
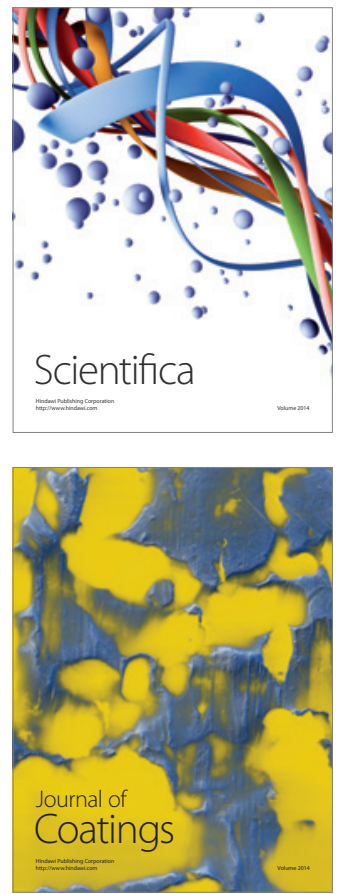
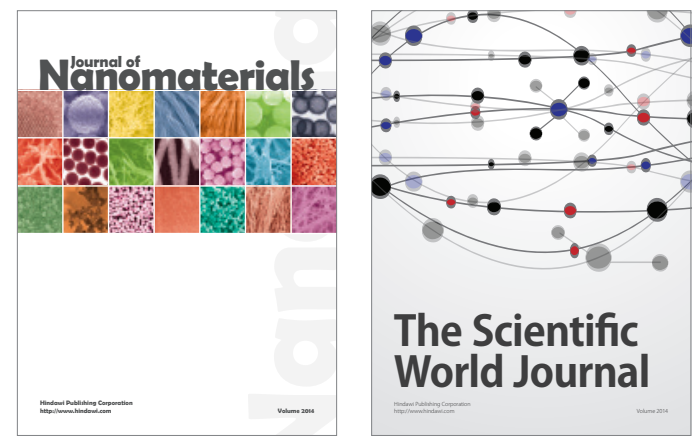

The Scientific World Journal
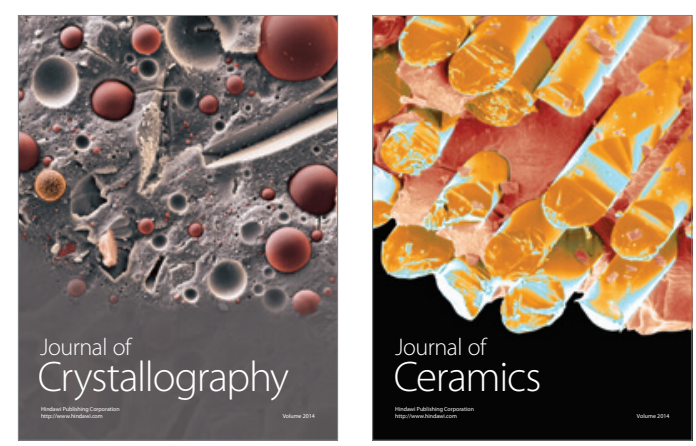
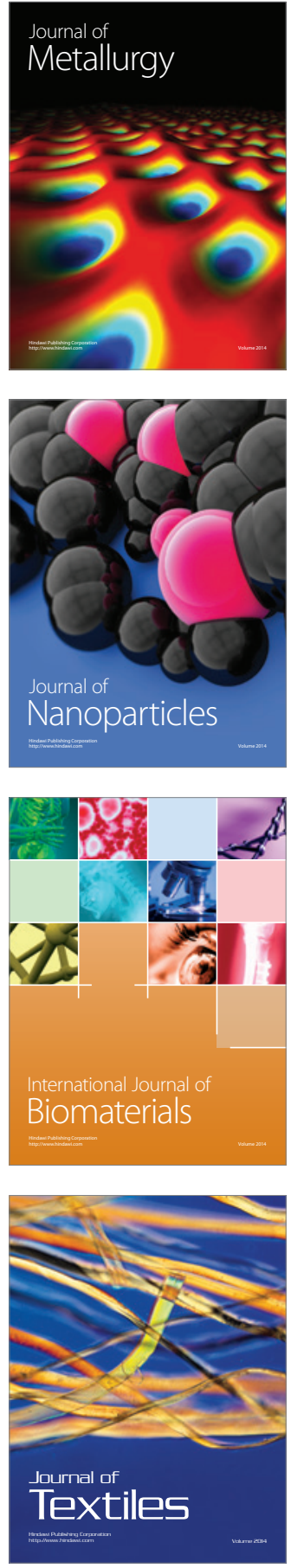